\title{
Investigation of Some Factors Associated with Utilization of Maternal Health Care Services by Adolescent Mothers in Tanzania
}

\author{
Elia Magwaja ${ }^{1}$, Jacqueline Minja ${ }^{2}$, Majige Selemani Budeba ${ }^{3}$ and Rocky R.J. Akarro ${ }^{4}$ * \\ ${ }^{1}$ University of Dar es Salaam, Department of Statistics, P.O. Box 35047, Dar es Salaam, \\ Tanzania. \\ ${ }^{2}$ Ifakara Health Institute, Plot 463, Kiko Avenue, Mikocheni, P.O. Box 78373, Dar es Salaam, \\ Tanzania \\ ${ }^{3}$ Bank of Tanzania, 2 Mirambo Street 11884, P.O. Box 2939, Dar es Salaam, Tanzania \\ ${ }^{4}$ University of Dar es Salaam, Department of Statistics, P.O. Box 35047, Dar es Salaam, \\ Tanzania. \\ Co-authors'e-mails: emagwaja@gmail.com; Jacquelineminja59@gmail.com; \\ majiges@yahoo.com \\ *Corresponding authore-mail: akarror@gmail.com
}

Received 26 Feb 2021, Revised 23 May 2021, Accepted 28 May 2021, Published May 2021

DOI: https://dx.doi.org/10.4314/tjs.v47i2.39

\begin{abstract}
This study examined some factors associated with the utilization of maternal health care services by adolescent mothers (15-19 years) in Tanzania in order to provide advice accordingly. The study used cross-sectional study of adolescent mothers aged 15-19 years using Demographic Health Survey and Malaria indicator Survey 2015/16 data. The dependent variables were number of antenatal care visits, the place where an adolescent mother delivered and post-natal checkup (adolescent mother's health checking after being discharged or after a home delivery). The independent variables were birth order, education level of a mother, marital status of a mother, media exposure, wealth index, distance to health facility. Multiple binary logistic regression was used to examine an association between each dependent variable and their respective independent variables. Data was analyzed using IBM SPSS statistics and STATA. This study used 550 adolescent mothers in the analysis. Majority of the adolescent mothers had less than four Antenatal Care (ANC) visits $(53.5 \%$ ), while $68.5 \%$ of adolescent mothers delivered at a health facility. Adolescent mothers with two or more children had less odds of having at least four ANCs compared to those with one child, whereas adolescent mothers with at least secondary education had greater odds of delivering at a health facility compared to those who had no education. Adolescent mothers who had at least four antenatal care visits and those who are married had greater odds of checking their health after being discharged compared to adolescent mothers who had less than 4 ANCs and single adolescent mothers. It was advised that provision of maternal education to young girls on the importance of safe delivery and health checking after delivery is very important to reduce adolescent maternal morbidity and mortality in the country.
\end{abstract}

Keywords: Adolescent; Maternal Health; Logistic regression; Chi-square.

\section{Introduction}

Maternal health, as described by the World Health Organisation (WHO), entails the health of a woman in the course of pregnancy, delivery and the period after childbirth. Whilst motherhood is often a positive and fulfilling 
experience, for too many women it is associated with sufferings, ill health and even sad and untimely deaths. It includes, among others, the health care services of family planning, preconception, prenatal as well as postnatal care services to provide a clear and suitable experience in most cases and lower maternal morbidity and mortality in other cases (WHO 2019).

As for adolescent mothers, who, according to Abor et al. (2011), include mothers within the range of 15-19 years inclusive, the situation of utilization of health care services when pregnant, during delivery and after delivery is worse. It is believed that adolescent mothers aged 15-19 are known to have greater risks of maternal morbidity and mortality because of their unique biological, sociological and economic statuses that may lead to potential complications of eclampsia, puerperal endometritis, and systemic infections than mothers aged 20-24 years.

During adolescence, pregnancy is more likely to be unplanned and childbirths are more prone to prematurity and are accompanied by high risks of complications in the course of delivery and death. In many countries, maternal mortality is a major cause of deaths among women of reproductive age, although most of those deaths can be prevented. Infants of adolescent mothers are also inclined to low birth weights, which can have a long run aftermath on their health and development. Singh et al. (2014a) pointed out that approximately 16 million girls aged 15 to 19 years and 2.5 million girls under 16 years give birth each year in developing regions, including Tanzania. Complications during pregnancy and childbirth are the leading causes of deaths for 15 to 19-year-old girls globally (WHO 2015). This, therefore, calls for even greater attention among the most vulnerable countries, most of which are in the sub-Saharan countries.

In Tanzania, the utilization of maternal health care services is still a big challenge. Tanzania has drastically attempted to prevent pregnancy in a society where engaging in sex before marriage is seen as shameful, reckless and immoral. In 2002, the laws were refreshed to not only exclude girls from becoming pregnant but barred them from reentering school once they become mothers. This approach, however, is not working because pregnancies among pupils are still a problem. According to the Tanzanian government, the number of pregnancies in girls aged 15-19 years continue to rise-increasing from $23 \%$ in 2010 to $27 \%$ in 2015 . This is higher than it was 20 years ago. Adolescent pregnancy is discouraged not because it is detrimental to itself, but because of its adverse social and economic impact on girls, their families and societies. Unmarried pregnant adolescent girls may face stigma or rejection by parents and peers and threats of violence. In addition, young women who become pregnant before reaching their 18 birthday are more likely to be exposed to assault within marriage or partnership. An estimated 5\% to $33 \%$ of girls aged 15-24 years who leave out schools in some countries do so due to early pregnancy or marriage (World Bank 2017). As for Tanzania, school dropouts among girls (Madeni et al. 2011) have accompanied pregnancy during adolescence. According to Integrated Regional Information Networks (IRIN), as quoted on the Women Living and Muslim Law website, school dropouts in Tanzania are higher in girls than boys and the common causes are teen pregnancy and teen marriages. Adolescent girls, following their subsequent lower education attainment, may be less skilled and have fewer opportunities for employment, often-perpetuating cycles of poverty, child marriage may therefore, reduce future earnings of young women by an estimated 9\% (World Bank 2017). Nationally, this can also have an economic cost, with countries losing the annual earnings that adolescent mothers would have collected over their lifetime if they had not been pregnant earlier.

Despite the fact that maternal health care utilization is essential for further improvement of maternal and child health among adolescent mothers aged 15-19 years, little is known about the current magnitude of use and factors 
influencing the use of these services in Tanzania. Studies addressing the issue of the utilization of maternal health care services among adolescent mothers in Tanzania are scanty. A few studies that do exist focus predominantly on utilization of maternal health care services to all women in the reproductive age. Methodologically, some of the available studies such as Joseph (2017) who dealt with antenatal care services during pregnancy and Samson (2012) who focused on factors affecting delivery services in health facilities put much emphasis on a single aspect among the components of maternal health care services. This may, in turn, underestimate the real problem of of maternal health care services among adolescent mothers. This work, therefore, focused on generating information on the utilization of maternal health care services by adolescent mothers (aged 15-19 years) in order to identify potential areas of intervention and equip policy makers with evidence to mount the focused intervention.

\section{Materials and Methods \\ Materials}

The area of this study is the United Republic of Tanzania. The country is divided into 31 administrative regions, of which 26 are in mainland and 5 are in Zanzibar. All adolescent mothers aged 15-19 years who have had children in the last five years before the year of doing the survey $(2015 / 16)$ were selected for this study. The study employed secondary data from the Tanzania Demographic Health Survey and Malaria Indicator Survey (TDHS-MIS). The TDHS-MIS survey is ideal for examining the number of antenatal care visits, delivery services and the postnatal care services among adolescent mothers aged 15-19 years. The survey covers diverse issues, which allow examining the drivers of the three aforementioned issues. For this purpose, from the data collected, this study extracted information on adolescent mothers aged 15-19 years.

\section{Methods}

In examining the utilization of maternal health care services by adolescent mothers aged 15-19 years, the selected independent variables were birth order, education level of a mother, marital status, media exposure, wealth index, and distance to health facility. The dependent variables were the number of antenatal care visits, postnatal checkup and delivery services. The dependent variables were coded as follows:

For the number of antenatal care visits, the WHO (2002) recommends that to improve quality of care and increase ANC visits coverage, a pregnant mother should have at least four ANC visits. Under this variable, therefore, there were two categories, the first category included adolescent mothers with less than four ANC visits which were coded as 0 , and the other category coded as 1 included adolescent mothers with at least four ANC visits. For delivery services (place of delivery), there were two categories coded 0 for adolescent mothers who did not deliver at a health facility and 1 for those who delivered at a health facility. For post-natal checkup (health checking after being discharged or home delivery), the two categories under this variable were coded as 0 for adolescent mothers who did not check their health after being discharged or home delivery, and 1 for adolescent mothers who checked their health after being discharged or home delivery.

The independent variables on the number of antenatal care visits and place of delivery were birth order, education level of a mother, marital status, media exposure, wealth index and distance to health facility. Independent variables on adolescent mother's health checking after being discharged or deliver at home were birth order, marital status, distance to the health facility, education level of the adolescent mother, place of residence and number of antenatal care visits. Statistically significant independent variables were picked for discussion as they are significant in explaining the effects observed in their respective dependent variables. 


\section{Model used: Logistic Regression}

Multiple logistic regressions were used to examine the association between each of the dependent variable as a dichotomous response variable and their respective independent variables. This was done after checking that all the assumptions underlying a logistic regression model were met. A multiple logistic regression predicts the probability that an observation is in one of the two categories of dichotomous dependent variable based on more than one independent variable that can be either continuous or categorical. The multiple logistic regression finds the equation that best predicts the value of a response variable, say $\mathrm{Y}$ for the values of predictor variables, say $X$. The response variable is the probability of obtaining a particular value of the nominal variable. This probability could take values from 0 to 1 . The limited range of this probability would present problematic issues if used directly in the regression, so the odds are opted instead. Taking the natural $\log$ of odds makes the variable more suitable for regression, so the result of logistic regression is in the form of;

$$
\begin{aligned}
\ln \left(\frac{p_{i}}{1-p_{i}}\right)=\beta_{0} & +\beta_{1} x_{1 i}+\beta_{2} x_{2 i}+\cdots \\
& +\beta_{n} x_{n i}
\end{aligned}
$$

For $\mathrm{i}=1,2,3, \ldots, \mathrm{n}$.

The slopes and the intercept of the bestfitting equation in multiple logistic regression are obtained using the maximum-likelihood method, rather than the least-squares method. After checking that the assumptions about the chi-square test were plausible, explanatory variables which were significant in the chisquare test were included in the binary logistic regression analysis.

\section{Results and Discussion}

The analysis included 550 adolescent mothers extracted from TDHS-MIS 2015/16 who had at least one child in the last five years before the time of doing the survey whose background information is shown below. The results from Table 1 show that; out of the 550 adolescent mothers, only $1.82 \%$ were 15 years old, while the majority $(46.55 \%)$ were 19 years old. For marital status, 181 (32.9\%) were single mothers, $238(43.3 \%)$ were married, whereas only $131(23.8 \%)$ were cohabiting. For birth order, $84.7 \%$ of adolescent mothers had one child and $15.3 \%$ had at least two children. The results show further that $78.5 \%$ of adolescent mothers were living in rural areas and $21.5 \%$ were living in urban areas.

Another important aspect determining the of maternal health care services among adolescent mothers in Tanzania revealed in Table 1 is the wealth index. The results show that most of the surveyed adolescent mothers were in the poorest group, which formed $28.5 \%$ of all adolescent mothers followed by poorer with $21.8 \%$ of all surveyed individuals. The middle and richer individuals formed $19.5 \%$ and $18.5 \%$ of all the respondents, respectively. The richest were the fewest forming only $11.6 \%$ of all the respondents.

Education level attained by the surveyed adolescent mother is another important background information presented in Table 1. The findings reveal that the majority of the respondents $(74.36 \%)$ had attended primary education, whereas those who had never gone to school and those who had at least secondary education had almost the same share $(12.91 \%$ and $12.73 \%$, respectively).

In explaining the role exposure to mass media on accessing maternal health care services among adolescent mothers in Tanzania, frequencies of watching television, reading newspapers or magazines and listening to radios within a week were observed. With an exception to the frequency of listening to radios, in other cases, the frequencies of exposure to mass media as displayed in Tables 1 are discouraging, as most of adolescent mothers are not exposed to mass media. The results show that $57.8 \%$ of adolescent women were not watching television at all, while $66 \%$ did not read newspapers or magazines at all. 
Tanz. J. Sci. Vol. 47(2), 2021

Table 1: Frequency distribution of the adolescent mothers by selected background characteristics, TDHS-MIS 2015/16

\begin{tabular}{|c|c|c|}
\hline Background characteristics & Frequency & percentage \\
\hline \multicolumn{3}{|l|}{ Demographic factors } \\
\hline \multicolumn{3}{|l|}{ Age } \\
\hline 15 & 10 & 1.82 \\
\hline 16 & 38 & 6.91 \\
\hline 17 & 85 & 15.45 \\
\hline 18 & 161 & 29.27 \\
\hline 19 & 256 & 46.55 \\
\hline \multicolumn{3}{|l|}{ Marital status } \\
\hline Single & 181 & 32.90 \\
\hline Married & 238 & 43.30 \\
\hline Cohabiting & 131 & 23.80 \\
\hline \multicolumn{3}{|l|}{ Birth order } \\
\hline One child & 466 & 84.70 \\
\hline At least two children & 84 & 15.30 \\
\hline \multicolumn{3}{|l|}{ Social- economic variables } \\
\hline \multicolumn{3}{|l|}{ Place of residence } \\
\hline Rural & 432 & 78.50 \\
\hline Urban & 118 & 21.50 \\
\hline \multicolumn{3}{|l|}{ Education level } \\
\hline No education & 71 & 12.31 \\
\hline Primary & 409 & 74.36 \\
\hline Secondary+ & 70 & 12.73 \\
\hline \multicolumn{3}{|l|}{ Wealth index } \\
\hline Poorest & 157 & 28.50 \\
\hline Poorer & 120 & 21.80 \\
\hline Middle & 107 & 19.50 \\
\hline Richer & 102 & 18.50 \\
\hline Richest & 64 & 11.60 \\
\hline \multicolumn{3}{|l|}{ Exposure to mass media } \\
\hline Not watching television at all & 318 & 57.80 \\
\hline Watching television at least once a week & 232 & 42.20 \\
\hline Not reading newspapers or magazine at all & 363 & 66.00 \\
\hline Reading newspapers or magazine at least once a week & 187 & 34.00 \\
\hline Not listening to radio at all & 148 & 26.90 \\
\hline Listening to radio at least once a week & 402 & 73.10 \\
\hline
\end{tabular}

Utilization of maternal health care services by adolescent mothers

Table 2 presents the extent to which adolescent mothers aged 15-19 years utilised maternal health care services. Table 2 presents the number of antenatal care visits, place of delivery and health checking after being discharged by adolescent mothers. For the variable number of antenatal care visits, WHO
(2002) recommends that for a healthy development of both, an expectant mother and an expected child, there should be at least four antenatal care visits before delivery. The results show that the majority of adolescent mothers $(53.50 \%)$ had less than four antenatal care visits, while $46.5 \%$ met the requirement as per WHO (2002) recommendation. 
Magwaja et al. - Investigation of some factors associated with maternal health care services ...

Table 2: Number of antenatal care visits

\begin{tabular}{lcc}
\hline Adolescent maternal health care services & Frequency & percentage \\
\hline $\begin{array}{l}\text { Number of antenatal care visits } \\
\text { Less than 4 ANC visits }\end{array}$ & 294 & 53.5 \\
At least 4 ANC visits & 256 & 46.5 \\
Place of delivery & & \\
No health facility & 173 & 31.45 \\
Health facility & 377 & 68.55 \\
Health checking after discharged/ deliver at home & & \\
$\begin{array}{l}\text { Not checked } \\
\text { checked }\end{array}$ & 497 & 90.36 \\
Distance to health facility & 53 & 9.64 \\
Big problem & & \\
Not a big problem & 249 & 45.3 \\
\hline
\end{tabular}

The place where a pregnant mother delivered a child is important for the health of both the mother and her newborn baby. It is an indicator of how mothers utilize maternal health care services at their disposal. The results presented in Table 2 show that $68.55 \%$ of adolescent mothers were found to have had delivered at a health facility, while $31.45 \%$ did not deliver at a health facility. Not delivering at a health facility might have been caused by factors such as; distance to a health facility, failure to attend clinics during pregnancy, costs of delivering at a health facility and ignorance of enormous benefits of delivering at a health facility.

For health checking after being discharged or delivery at home, the statistics are not impressive at all. The findings showed that about $90 \%$ of all the surveyed adolescent mothers did not tend to check their health, while about $10 \%$ tended to do so. This might have been attributed by factors such as, among others, ignorance of an adolescent mother about the importance of health checking after delivery and distance to health facility, especially in rural settings. Hanson et al. (2015) found that the difficulty of utilizing maternal health care services in rural areas of Tanzania comes with the fact that most mothers live far from the health facilities (median distance of $18.0 \mathrm{~km}$ ) and are less educated to know the importance of utilizing the services.
The results presented in Table 2 show that $54.7 \%$ of adolescent mothers responded that the distance to the health facility was not a big problem, whereas the rest $(45.3 \%)$ had a big problem with the distance to the health facility. Distance to a health facility may either encourage or discourage those who require health care services. Whilst long distances to health facilities discourage the needy, short distances attract them. Kiango (2015) insisted that the distance between a health facility and the adolescent mother's home is also important in determining the utilization of health care services. The author points out that, while longer distances are discouraging, shorter distances are welcoming.

\section{Associations between dependent and independent variables}

Tables 3, 4 and 5 present the associations between the number of antenatal care visits, place of delivery and adolescent mother's health checking after being discharged or after a home delivery as dependent variables and their respective independent variables. The status of the association between dependent variables and their respective independent variables was assessed by using the $\mathrm{p}$-value. A p-value of less than 0.1 (Schumm et al. 2013), less than 0.05 and less than 0.01 indicate that the associations between dependent variables and their respective independent variables are 
statistically significant at $\alpha=0.1,0.05$ and 0.01 , respectively. In running the multiple binary logistic regression, therefore, all the independent variables which were statistically significantly associated at these three levels of significance with dependent variables were included in the model.

Table 3 presents cross-tabulation between independent variables and the number of antenatal care visits. The results reveal that; birth order, frequency of watching television, type of place of residence, wealth index were statistically significant at $1 \%$ level of significance, while current marital status and frequency of listening to radio were statistically significant at $10 \%$ level of significance and frequency of reading newspapers or magazines was statistically significant at $5 \%$ level of significance.

Table 3: Association between independent variables and number of antenatal care visits

\begin{tabular}{|c|c|c|c|c|}
\hline \multirow[t]{2}{*}{ Independent variables } & \multicolumn{4}{|c|}{ Antenatal care visits } \\
\hline & $\begin{array}{l}\text { At least four visits } \\
(\%)\end{array}$ & $\begin{array}{l}\text { Less than four } \\
\text { visits }(\%)\end{array}$ & Total & P-value \\
\hline \multicolumn{5}{|l|}{ Birth order } \\
\hline One child & $229(49.14)$ & $237(50.86)$ & 466 & \\
\hline Two or more children & $27(32.14)$ & $57(67.86)$ & 84 & $0.004 * * *$ \\
\hline \multicolumn{5}{|l|}{ Marital status } \\
\hline Single & $72(39.78)$ & $109(60.22)$ & 181 & \\
\hline Married & $119(50)$ & $119(50)$ & 238 & \\
\hline Living together & $65(49.62)$ & $66(50.38)$ & 131 & $0.083 *$ \\
\hline \multicolumn{5}{|l|}{ Distance to health facility } \\
\hline Big problem & $109(43.78)$ & $140(56.22)$ & 249 & \\
\hline Not a big problem & $147(48.84)$ & $154(51.16)$ & 301 & 0.236 \\
\hline \multicolumn{5}{|l|}{ Frequency of listening radio } \\
\hline Not listening radio at all & $62(41.89)$ & $86(58.11)$ & 148 & \\
\hline Listening radio at least once a week & $194(48.26)$ & $208(51.74)$ & 402 & $0.083 *$ \\
\hline \multicolumn{5}{|l|}{$\begin{array}{l}\text { Frequency of reading newspaper or } \\
\text { magazine }\end{array}$} \\
\hline $\begin{array}{l}\text { Not reading newspapers or magazine at } \\
\text { all }\end{array}$ & $158(43.53)$ & $205(56.47)$ & 363 & \\
\hline $\begin{array}{l}\text { Reading newspapers or magazine at } \\
\text { least once a week }\end{array}$ & $98(52.41)$ & $89(47.59)$ & 187 & $0.017 * *$ \\
\hline \multicolumn{5}{|l|}{ Frequency of watching television } \\
\hline Not watching television at all & $133(41.82)$ & $185(58.18)$ & 318 & \\
\hline Watching television at least once & $123(53.02)$ & $109(46.98)$ & 232 & $0.003 * * *$ \\
\hline \multicolumn{5}{|l|}{ Highest education level } \\
\hline No education & $28(39.44)$ & $43(60.56)$ & 71 & \\
\hline Primary & $191(46.70)$ & $218(53.30)$ & 409 & \\
\hline Secondary+ & $37(52.86)$ & $33(47.14)$ & 70 & 0.277 \\
\hline \multicolumn{5}{|l|}{ Place of residence } \\
\hline Urban & $75(63.56)$ & $43(36.44)$ & 118 & \\
\hline Rural & $181(41.90)$ & $251(58.10)$ & 432 & $0.000 * * *$ \\
\hline \multicolumn{5}{|l|}{ Wealth index } \\
\hline Poorest & $57(36.31)$ & $100(63.69)$ & 157 & \\
\hline Poor & $50(41.67)$ & $70(58.33)$ & 120 & \\
\hline Middle & $47(43.93)$ & $60(56.07)$ & 107 & \\
\hline Richer & $59(57.84)$ & $43(42.16)$ & 102 & \\
\hline Richest & $43(67.19)$ & $21(32.81)$ & 64 & $0.000 * * *$ \\
\hline
\end{tabular}


The results show that $49 \%$ of adolescent mothers who had one child had at least four antenatal care visits, while those with two or more children $32.14 \%$ had less than four antenatal care visits. The results from Table 3 show further that among adolescent mothers, $50 \%$ of the married adolescent mothers had at least four antenatal care visits compared to $39.78 \%$ and $49.62 \%$ adolescent mothers who were single and cohabiting, respectively.

Adolescent mothers who read newspapers or magazine at least once a week had higher percentages $(52.41 \%)$ of having at least four antenatal care visits compared to $43.53 \%$ of those who did not read newspapers or magazine at all. About 53\% of adolescent mothers who watched television at least once a week, tended to have at least four antenatal care visits compared to $42 \%$ of those who did not watch television at all. On the other hand, adolescent mothers who tended to listen to radio at least once a week, $48.26 \%$ attended at least four antenatal care visits compared to adolescent mothers who did not listen to radio at all $(41.89 \%)$.

The results in Table 3 show further that $63.56 \%$ of adolescent mothers living in urban areas had at least four antenatal care visits, while the corresponding figure for those living in rural areas was only $41.90 \%$.

Results in Table 3 reveal that the extent of fulfilling the recommended number of antenatal care visits is proportional to the earning of an adolescent mother. The results show that $67.19 \%$ of the richest adolescent mothers had at least four antenatal care visits compared to richer $(57.84 \%)$, middle-income earners $(43.93 \%)$, poor $(41.67 \%)$ and the poorest $(36.31 \%)$.

Table 4 shows the associations between independent variables and place of delivery.
The results depict that birth order, frequency of watching television, frequency of reading newspapers or magazines, highest education level, place of residence and wealth index were statistically significant at $1 \%$ level of significance, while distance to healthy facility was statistically significant at $10 \%$ level of significance and frequency of listening to radio was statistically significant at 5\% level of significance. The results in Table 4 show that $72.75 \%$ of adolescent mothers who had one child delivered at a health facility compared to $45.24 \%$ of those who had at least two children. Furthermore, $71.76 \%$ of adolescent mothers aged 15-19 years who were cohabiting delivered at a health facility, while married and single had almost the same percentage $(67.23 \%$ and $67.96 \%$, respectively) to deliver at a health facility.

Results from Table 4 show also that $71.76 \%$ of all adolescent mothers who delivered at a health facility responded that distance to a health facility was not problematic in utilizing the maternal health care services as opposed to $64.66 \%$ of those who delivered at health facility who responded that distance to a health facility was problematic. On the other hand, adolescent mothers who tended to read newspapers or magazines at least once a week had a $77.54 \%$ chance of delivering at a health facility against who did not read newspapers or magazines at all $(63.91 \%)$. It is also evident from Table 4 that adolescent mothers who tended to listen to radio and watched television at least once a week had a higher percentage (71.39\% and $75.86 \%$, respectively) compared to not listening to radio or watching television at all $(60.81 \%$ and $63.21 \%$, respectively). 
Tanz. J. Sci. Vol. 47(2), 2021

Table 4: Association between independent variables and place of delivery

\begin{tabular}{|c|c|c|c|c|}
\hline \multirow[t]{2}{*}{ Independent variables } & \multicolumn{4}{|c|}{ Place of delivery } \\
\hline & $\begin{array}{l}\text { At health facility } \\
(\%)\end{array}$ & $\begin{array}{l}\text { Not at health } \\
\text { facility }(\%)\end{array}$ & $\begin{array}{c}\text { Total } \\
(\%)\end{array}$ & P-value \\
\hline \multicolumn{5}{|l|}{ Birth order } \\
\hline One child & $339(72.75)$ & $127(27.25)$ & 466 & \\
\hline Two or more children & $38(45.24)$ & $46(54.76)$ & 84 & $0.000 * * *$ \\
\hline \multicolumn{5}{|l|}{ Marital status } \\
\hline Single & $123(67.96)$ & $58(34.02)$ & 181 & \\
\hline Married & $160(67.23)$ & $78(32.77)$ & 238 & \\
\hline Living together & $94(71.76)$ & $37(28.24)$ & 131 & 0.655 \\
\hline \multicolumn{5}{|l|}{ Distance to health facility } \\
\hline Big problem & $161(64.66)$ & $88(35.34)$ & 249 & \\
\hline Not a big problem & $216(71.76)$ & $85(28.24)$ & 301 & $0.074 *$ \\
\hline \multicolumn{5}{|l|}{ Frequency of listening radio } \\
\hline Not listening radio at all & $90(60.81)$ & $58(39.19)$ & 148 & \\
\hline $\begin{array}{l}\text { Listening radio at least once a } \\
\text { week }\end{array}$ & $287(71.39)$ & $115(28.61)$ & 402 & $0.014 * *$ \\
\hline \multicolumn{5}{|l|}{$\begin{array}{l}\text { Frequency of reading } \\
\text { newspaper or magazine }\end{array}$} \\
\hline $\begin{array}{l}\text { Not reading newspapers or } \\
\text { magazine at all }\end{array}$ & $232(63.91)$ & $131(36.09)$ & 363 & \\
\hline $\begin{array}{l}\text { Reading newspapers or } \\
\text { magazine }\end{array}$ & $145(77.54)$ & $42(22.46)$ & 187 & $0.004 * * *$ \\
\hline \multicolumn{5}{|l|}{$\begin{array}{l}\text { Frequency of watching } \\
\text { television }\end{array}$} \\
\hline Not watching television at all & $201(63.21)$ & $117(36.79)$ & 318 & \\
\hline Watching television & $176(75.86)$ & $56(24.14)$ & 232 & $0.001 * * *$ \\
\hline \multicolumn{5}{|l|}{ Highest education level } \\
\hline No education & $35(49.30)$ & $36(50.70)$ & 71 & \\
\hline Primary & $280(68.46)$ & $129(31.54)$ & 409 & \\
\hline Secondary+ & $62(88.57)$ & $8(11.43)$ & 70 & $0.000 * * *$ \\
\hline \multicolumn{5}{|l|}{ Place of residence } \\
\hline Urban & $103(87.29)$ & $15(12.71)$ & 118 & \\
\hline Rural & $274(63.43)$ & $158(36.57)$ & 432 & $0.000 * * *$ \\
\hline \multicolumn{5}{|l|}{ Wealth index } \\
\hline Poorest & $88(56.05)$ & $69(43.95)$ & 157 & \\
\hline Poor & $71(59.17)$ & $49(40.83)$ & 120 & \\
\hline Middle & 77 (71.96) & $30(28.04)$ & 107 & \\
\hline Richer & $83(81.37)$ & $19(18.63)$ & 102 & \\
\hline Richest & $58(90.63)$ & $6(9.38)$ & 64 & $0.000 * * *$ \\
\hline
\end{tabular}

For higher education level, $88.57 \%$ of adolescent mothers who had secondary education and above tended to deliver at a health facility compared to adolescent mothers with no education and primary education level who had $49.30 \%$ and $68.46 \%$ chances of delivering at a health facility, respectively. It is also observed from Table 4 that about $87 \%$ of adolescent mothers aged 15-19 years living in urban areas delivered at a health facility compared to $63.43 \%$ of those who live in rural areas. The results in Table 4 also show that 
$90.63 \%$ of adolescent mothers of the richest adolescent mothers tend to deliver at a health facility compared to $81.37 \%, 71.96 \%, 59.17 \%$ and $56.05 \%$ of the richer, middle-income earners, poor and those who are the poorest, respectively.

Table 5 shows the results of crosstabulation between independent variables and adolescent mother's health being checked after being discharged. The results reveal that the number of antenatal care visits was statistically significant at $5 \%$ level of significance, whereas birth order and marital status were significant at $10 \%$ and $5 \%$ level, respectively. The results from Table 5 are a good testament that shows that most of the adolescent mothers do not check their health after being discharged or after a home delivery.

Table 5: Association between independent variables and adolescent mother's health checking after being discharged

\begin{tabular}{|c|c|c|c|c|}
\hline \multirow[t]{2}{*}{ Independent variables } & \multicolumn{3}{|c|}{ Respondents health status } & \multirow[b]{2}{*}{ P-value } \\
\hline & $\begin{array}{l}\text { Health checked } \\
(\%)\end{array}$ & Not checked (\%) & Total & \\
\hline Birth order & $49(10.63)$ & $412(89.37)$ & 461 & \\
\hline One child & $4(4.76)$ & $80(95.24)$ & 84 & $0.095^{*}$ \\
\hline \multicolumn{5}{|l|}{ Two or more children } \\
\hline \multicolumn{5}{|l|}{ Marital status } \\
\hline Single & $10(5.56)$ & $170(94.44)$ & 180 & $0.05 * *$ \\
\hline Married & $26(10.97)$ & $211(89.03)$ & 237 & \\
\hline Living together & $17(13.28)$ & $111(86.72)$ & 128 & \\
\hline \multicolumn{5}{|l|}{ Distance to health facility } \\
\hline Big problem & $27(10.98)$ & $219(89.02)$ & 246 & 0.371 \\
\hline Not a big problem & $26(8.70)$ & $273(91.30)$ & 299 & \\
\hline \multicolumn{5}{|l|}{ Highest education level } \\
\hline No education & $8(11.27)$ & $63(88.73)$ & 71 & 0.284 \\
\hline Primary & $35(8.64)$ & $370(91.36)$ & 405 & \\
\hline Secondary+ & $10(14.49)$ & $59(85.51)$ & 69 & \\
\hline \multicolumn{5}{|l|}{ Place of residence } \\
\hline Urban & $13(11.02)$ & $105(88.98)$ & 118 & 0.593 \\
\hline Rural & $40(9.37)$ & $387(90.63)$ & 427 & \\
\hline \multicolumn{5}{|l|}{$\begin{array}{l}\text { Number of antenatal care } \\
\text { visits }\end{array}$} \\
\hline Less than four visits & $21(7.24)$ & $269(92.76)$ & 290 & $0.037 * *$ \\
\hline At least four visits & $32(12.55)$ & $223(87.45)$ & 255 & \\
\hline
\end{tabular}

The results from Table 6 show that for an adolescent mother who had two or more children $(A O R=0.563: 95 \%$ C.I: $0.338-0.938)$ had less odds of having at least four antenatal care visits compared to an adolescent mother who had one child. The odds ratio for the variable birth order for an adolescent mother with at least two children was 0.563 , which implies that an adolescent mother who had two or more children was $43.7 \%$ less likely to have at least four antenatal care visits than an adolescent mother with one child. This might have been caused by the fact that unlike experienced mothers with two or more children, adolescent mothers with one child, as a result of lacking experience on maternal health, have fear on maternal complications hence find it healthier going for antenatal care services. This result is similar to the results by Singh et al. (2014a) who showed that mothers with two or more children are less likely to 
receive full antenatal care services than mothers with only one child.

Table 6 shows also that, for the variable marital status, the category for married adolescent mothers was statistically significant at $10 \%$ level of significance compared to single adolescent mothers. However, as suggested by Polissar and Diehr (1982), since the whole construct is not statistically significant ( $p$-value $=0.134$ ), it makes no sense to test for the significance of individual categories.

Table 6: Multiple binary logistic regression on number of antenatal care visits

\begin{tabular}{|c|c|c|c|c|}
\hline \multirow[b]{2}{*}{ Independent variable } & \multicolumn{4}{|c|}{$95 \%$ C.I } \\
\hline & AOR & Lower & Upper & P-value \\
\hline \multicolumn{5}{|l|}{ Birth order } \\
\hline One child & 1 & & & \\
\hline Two or more children & 0.563 & 0.338 & 0.938 & $0.028 * * *$ \\
\hline Marital status & & & & 0.134 \\
\hline Single & 1 & & & \\
\hline Married & 1.500 & 0.999 & 2.252 & 0.051 \\
\hline Cohabiting & 1.387 & 0.867 & 2.219 & 0.173 \\
\hline \multicolumn{5}{|l|}{ Frequency of listening radio } \\
\hline Not listening radio at all & 1 & & & \\
\hline Listening radio at least once a week & 1.002 & 0.652 & 1.541 & 0.993 \\
\hline \multicolumn{5}{|l|}{ Frequency of reading newspapers or magazine } \\
\hline Not reading newspapers or magazine at all & 1 & & & \\
\hline Reading newspapers or magazine at least once a week & 1.181 & 0.800 & 1.745 & 0.403 \\
\hline \multicolumn{5}{|l|}{ Frequency of watching television } \\
\hline Not watching television at all & 1 & & & \\
\hline Watching television at least once a week & 1.096 & 0.729 & 1.648 & 0.660 \\
\hline
\end{tabular}

Table 7 shows that adolescent mothers with two or more children $(\mathrm{AOR}=0.358 ; 95 \% \mathrm{CI}$ 0.215-0.596) had less odds of delivering at a health facility against those with one child at 1 $\%$ level of significance $(\mathrm{p}$-value $=0.000)$. This implies that adolescent mothers with two or more children are $64.2 \%$ less likely to deliver at a health facility compared to adolescent mothers with only one child. These results are similar to the results by Singh et al. (2014b) who also found that mothers with two or more children are less likely to deliver at a hospital than those with one child. This might be because adolescent mothers with two or more children think that they do not need to deliver at the hospital because of the experience they have had from the first child compared to adolescent mothers in their first birth. Table 7 shows further that the category of adolescent mothers who were reading newspapers or magazines at least once a week ( $\mathrm{AOR}=1.471$; $95 \%$ C.I $=0.930-2.328$ ) had more odds at $10 \%$ level of significance of delivering at a health facility compared to those who were not reading newspapers or magazine at all. For the frequency of reading newspapers or magazine at least once a week, the odds ratios were 1.471. This implies that, adolescent mothers who tend to read newspapers or magazines at least once a week are $47.1 \%$ more likely to deliver at a health facility compared to adolescent mothers who do not read newspapers or magazine at all. These results are similar to the results by Banke-Thomas et al. (2017) who, through their research on factors influencing utilization of maternal health care services by adolescent mothers inlow and in-middle income countries explain media exposure as the most significant factor which influences the utilization of maternal 
Magwaja et al. - Investigation of some factors associated with maternal health care services ...

health care services by adolescent mother inlow and in-middle income countries. This may, reasonably, be because adolescent mothers who read newspapers or magazines at least once a week are more exposed to mass media, which may, in turn, imply being more exposed to the importance of utilizing the health care services compared to adolescent mothers who do not read newspapers or magazine at all.

Table 7: Multiple binary logistic regression on a place of delivery

\begin{tabular}{|c|c|c|c|c|}
\hline \multirow[b]{2}{*}{ Independent variable } & \multicolumn{4}{|c|}{$95 \%$ C.I } \\
\hline & AOR & Lower & Upper & $\mathrm{P}$-value \\
\hline \multicolumn{5}{|l|}{ Birth order } \\
\hline One child & 1 & & & \\
\hline Two or more children & 0.358 & 0.215 & 0.596 & $0.000 * * *$ \\
\hline \multicolumn{5}{|l|}{ Distance to health facility } \\
\hline Big problem & 1 & & & \\
\hline Not a big problem & 1.143 & 0.768 & 1.701 & 0.511 \\
\hline \multicolumn{5}{|l|}{ Frequency of listening radio } \\
\hline Not listening radio at all & 1 & & & \\
\hline Listening radio at least once a week & 1.022 & 0.640 & 1.63 & 0.928 \\
\hline \multicolumn{5}{|l|}{ Frequency of reading newspapers or magazine } \\
\hline Not reading newspapers or magazine at all & 1 & & & \\
\hline $\begin{array}{l}\text { Reading newspapers or magazine at least once a } \\
\text { week }\end{array}$ & 1.471 & 0.930 & 2.328 & $0.099 *$ \\
\hline \multicolumn{5}{|l|}{ Frequency of watching television } \\
\hline Not watching television at all & 1 & & & \\
\hline Watching television at least once a week & 1.029 & 0.652 & 1.623 & 0.903 \\
\hline Education level & & & & $0.070^{*}$ \\
\hline No education & 1 & & & \\
\hline Primary & 1.415 & 0.810 & 2.473 & 0.223 \\
\hline Secondary+ & 3.096 & 1.185 & 8.088 & $0.021 * * *$ \\
\hline \multicolumn{5}{|l|}{ Place of residence } \\
\hline Urban & 1 & & & \\
\hline Rural & 0.494 & 0.241 & 1.012 & $0.054 *$ \\
\hline Wealth index & & & & 0.151 \\
\hline Poorest & 1 & & & \\
\hline Poor & 0.984 & 0.594 & 1.631 & 0.951 \\
\hline Middle & 1.546 & 0.883 & 2.709 & 0.127 \\
\hline Richer & 1.863 & 0.956 & 3.631 & 0.068 \\
\hline Richest & 2.649 & 0.877 & 7.998 & 0.084 \\
\hline
\end{tabular}

**significant at $\mathrm{p}=0.05, *$ significant at $\mathrm{p}=0.1, * * *$ significant at $\mathrm{p}=0.01$

From Table 7, the results reveal that for the whole construct for the variable highest level education of an adolescent mother was statistically significant at $10 \%$ level of significance. However, only adolescent mothers who had at least secondary education's category $(\mathrm{AOR}=3.096 ; 95 \%$ C.I $=1.185$ 8.088) had more odds of delivering at a health facility at $5 \%$ level of significance compared to the no education category. For the highest education level of the adolescent, the odds ratio is 3.096 for adolescent mothers who have at least secondary education compared to the no education category. The results imply that an adolescent mother who had a secondary+ education is $209.6 \%$ more likely to deliver at a health facility than an adolescent mother who has never gone to school at all. This may be 
opined that adolescent mothers who have secondary school and above may have enough knowledge on the importance of delivering at a safer place (health facility) compared to those who have no education at all. These results are similar to the results by Abor et al. (2011) who found that education level of a mother plays an important role as one of the most important factors that influence the utilization and change in utilization of maternal health services. The study, therefore, goes on revealing out that women with a high level of education tend to utilize more maternal health care services compared to those with low level of education. The results are also similar to those of Samson (2012) who, through the study on utilization and factors affecting delivery in health facility among recently delivered women in Nkasi District, points out that education of the respondent was highly associated with delivery in a health facility (p-value $=0.01$ ). The study further shows that women with secondary education are more likely to deliver at a health facility compared to those with no education. Table 7 also shows that for place of residence, rural category $(\mathrm{AOR}=0.494,95 \%$ C.I $=0.241$ 1.012) had less odds of delivering at a health facility at 10 per cent level of significance ( $p$ value $=0.054)$ compared to the urban setting The odds ratio for adolescent mother who lives in the rural area is 0.499 . This implies that an adolescent mother who lives in a rural area is $50.1 \%$ less likely to deliver at a health facility compared to an adolescent mother who lives in urban areas. This result is similar to a result from Shahabuddin et al. (2015) who found that the use of maternal health care services to adolescent women in rural areas is less than in urban areas. This may be because adolescent mothers who live in rural areas have, admittedly, different challenges compared to those who live in urban areas such as; poor transportation systems to/from health facilities, inadequate health facilities and some other similar reasons. For the variable wealth index, since the whole construct is not statistically significant $(\mathrm{p}$-value $=0.151)$, therefore, the significance of individual categories cannot be discussed even though some categories (richer and richest) are statistically significant at $10 \%$ level of significance.

From table 8 , the results reveal that the whole construct for the variable marital status is statistically significant at $10 \%$ level of significance (since the p-value is 0.091). For the significance of the categories, those which were classified as married ( $\mathrm{AOR}=1.951 ; 95 \%$ C.I $=0.911-4.180)$ and cohabiting $(\mathrm{AOR}=$ 2.465; 95\% C.I $=1.084-5.603$ ) had more odds of checking their health after being discharged at $10 \%$ and $5 \%$ per cent levels of significance compared to single adolescent mothers, respectively. The odds ratios for the two categories were 1.951 and 2.465 , respectively. These results imply that a married adolescent mother is $95.1 \%$ better off going for a postnatal checkup after being discharged or after delivering at home than a single adolescent mother. As for cohabiting adolescent mothers, the results imply that they are $146.5 \%$ more likely to go for a postnatal checkup after being discharged or after a home delivery than single adolescent mothers.

For the variable number of antenatal care visits; the results show that adolescent mothers who had at least four antenatal care visits $(\mathrm{AOR}=1.685 ; 95 \%$ C.I $=0.939-3.024)$ had a greater likelihood of checking their health after being discharged or delivering at home than those with less than four antenatal care visits at 10 per cent level of significance. The odds ratio for the variable number of antenatal care visits for the category of adolescent mothers with at least four antenatal care visits is 1.685 . This implies that an adolescent mother with at least four antenatal care visits is $68.5 \%$ more likely to check her health after being discharged or after a home delivery than an adolescent mother with less than four antenatal care visits. This may be because adolescent mothers who had at least four antenatal care visits are more exposed to the education on the importance of checking their health after delivery provided during the visits. 
Magwaja et al. - Investigation of some factors associated with maternal health care services ...

Table 8: Multiple binary logistic regression on adolescent mother's health being checked after being discharged or after a home delivery

\begin{tabular}{|c|c|c|c|c|}
\hline \multirow[t]{2}{*}{ Independent variable } & \multicolumn{4}{|c|}{$95 \%$ C.I } \\
\hline & AOR & Lower & Upper & P-value \\
\hline \multicolumn{5}{|l|}{ Birth order } \\
\hline One child & 1 & & & \\
\hline Two or more children & 0.463 & 0.161 & 1.334 & 0.154 \\
\hline Marital status & & & & $0.091 *$ \\
\hline Single & 1 & & & \\
\hline Married & 1.951 & 0.911 & 4.18 & $0.085 *$ \\
\hline Cohabiting & 2.465 & 1.084 & 5.603 & $0.031 * *$ \\
\hline \multicolumn{5}{|c|}{ Number of antenatal care visits } \\
\hline Less than 4 ANC visits & 1 & & & \\
\hline At least 4 ANC visits & 1.685 & 0.939 & 3.024 & $0.080 *$ \\
\hline
\end{tabular}

\section{Conclusion}

Chi-square test and Logistic regression were applied to assess the association and magnitude of association between independent and dependent variables. Variables with statistical association at $10 \%$ level of significance were included in the multiple logistic regression for obtaining the final model. The results show that the many adolescent mothers $(84.7 \%)$ had one child. For the highest education level attained by adolescent mothers, $74.36 \%$ had primary education and few of them had at least secondary education. Majority of adolescent mothers were married (43.3\%). On getting medical help from the health facility, about $55 \%$ of the adolescent mothers reported that distance to health facility was not a big problem and the remaining $45 \%$ reported otherwise. For the variable wealth index, $28.5 \%$ were the poorest, $21.9 \%$ poor, $19.5 \%$ middle, $18.5 \%$ rich and only $11.6 \%$ were in the richest category. For the variable, type of place of residence, the findings showed that $78.5 \%$ of the adolescent mothers were living in rural areas whereas $21.5 \%$ were living in the urban areas. The results on the multiple logistic regression models show that for the variable 'number of antenatal care visits' there is only one variable which is statistically significant which is birth order. For delivery services, birth order, frequency of reading newspapers or magazine, education of adolescent mother and place of residence were statistically significant and for the post-natal checkup (adolescent health checking after being discharged or delivery at home), marital status and number of antenatal care visits were statistically significant.

The findings showed further that the category of adolescent mothers who were reading newspapers or magazines at least once a week was statistically significantly associated with place of delivery. It was also seen from the results that marital status of an adolescent mother and number of antenatal care visits were significant in determining the extent of an adolescent mother going for a postnatal checkup after being discharged or after home delivery.

The study concluded that adolescent mothers with higher education tend to use and utilise more antenatal health care services compared to those who are less educated, which implies that education plays a great role in utilizing maternal health care services among adolescent mothers. The Government may, therefore, continuously, keep on disseminating information concerning antenatal care services, delivery services and postnatal services to enhance accessibility to these important messages by pregnant adolescent women as they are, probably, the most vulnerable group in the childbearing years. 
Place of delivery plays a great role in determining the health of a mother and a newborn child. An adolescent mother who delivers at a health facility has a greater likelihood of being safe compared to an adolescent mother who delivers at home or a place with no health service providers. As a result, the government may improve the quality of delivery services by ensuring that there is adequate number of health care centres especially in rural areas where the situation is worse and the monitoring should be strict at all levels. The government should provide education to adolescent mothers on how they can utilise effectively maternal health care services by setting up priorities on educating women.

\section{Declaration of conflict of interest}

There is no conflict of interest to report.

Ethical clearance: All the ethical standards for publication were observed.

\section{References}

Abor PA, Abekah-Nkrumah G, Sakyi K, Adjasi CK and Abor J 2011 The socio-economic determinants of maternal health care utilization in Ghana. Int. J. Soc. Econ. 38(7): 628-648.

Banke-Thomas OE, Banke-Thomas AO, and Ameh CA 2017 Factors influencing utilization of maternal health services by adolescent mothers in low-and middle-income countries: a systematic review. BMC Pregnancy Childbirth 17(1): 1-14.

Hanson C, Gabrysch S, Mbaruku G, Cox J, Mkumbo E, Manzi F, Schellenberg J and Ronsmans C 2015 Access to maternal health services: geographical inequalities, United Republic of Tanzania. Bull. World Health Organ. 95(12): 810.

Joseph A 2017 Analysis of factors influencing antenatal care visits among pregnant women. Master's Dissertation, University of Dar es Salaam.
Kiango PM 2015 Factors affecting utilization of maternal health care services among pregnant mothers: A case of Bumbuli District Council. PhD thesis, Mzumbe University.

Madeni F, Horiuchi S and Iida M 2011 Evaluation of a reproductive health awareness program for adolescence in urban Tanzania-A quasi-experimental pre-test post-test research. Reprod. Health 8(1): 1-9.

Polissar L and Diehr P 1982 Regression analysis in health services research: the use of dummy variables. Med. Care 20(9): 959-966.

Samson G 2012 and factors affecting delivery in health facility among recent delivered women in Nkasi District. PhD dissertation, Muhimbili University of Health and Allied Sciences.

Schumm WR, Pratt KK, Hartenstein JL, Jenkins BA and Johnson GA 2013 Determining statistical significance (alpha) and reporting statistical trends: Controversies, issues and facts. Compr. Psychol. 2: 03-CP.

Shahabuddin ASM, Delvaux T, Abouchadi S, Sarker M and De Brouwere V 2015 of maternal health services among adolescent women in Bangladesh: A scoping review of the literature. Trop. Med. Int. Health 20(7): 822-829.

Singh A, Kumar A and Pranjali P 2014a Utilization of maternal healthcare among adolescent mothers in urban India: evidence from DLHS-3. PeerJ. 2: e592.

Singh D, Lample M and Earnest J 2014b The involvement of men in maternal health care: cross-sectional, pilot case studies from Maligita and Kibibi, Uganda. Reprod. Health 11(1): 1-8.

World Health Organization (WHO) 2002 WHO antenatal care randomized trial: Manual for the implementation of the new model (No. WHO/RHR/01.30), Geneva, Switzerland.

World Bank Group 2017 World Development Indicators online 2017. World Bank, Washington, DC.

WHO 2015 World report on ageing and health. WHO Press, Geneva, Switzerland. 247 p.

WHO 2019 Maternal Health. Retrieved April 28, 2019, from https://www.who.int/maternalhealth/en/. 